\title{
MANEJO DA TEMPERATURADO AR NA SECAGEM INTERMITENTE DE SEMENTES DE ARROZ IRRIGADO ${ }^{1}$
}

\author{
CRISTINE THOMAZSARAVIA², WOLMER BROD PERES ${ }^{3}$, JOELRISSO $^{4}$
}

\begin{abstract}
RESUMO - O trabalho visou à minimização das perdas na qualidade fisiológica das sementes de arroz irrigado pelo adequado uso de temperaturas de condicionamento do ar durante a secagem intermitente. Sementes de arroz, cultivar EL Paso L-144, foram secadas em secador industrial intermitente, marca Pampeiro, fluxo misto, com capacidade estática de 11000 kg, em quatro manejos do ar de secagem: 1) secagem com temperatura do ar constante a $40^{\circ} \mathrm{C}$; 2) secagem com temperatura do ar constante a $60^{\circ} \mathrm{C}$; 3 ) secagem com temperatura do ar crescente (até $60^{\circ} \mathrm{C}$ ) nas primeiras duas horas e a partir da segunda hora constante a $60^{\circ} \mathrm{C}$; 4) secagem com temperatura do ar crescente (até $60^{\circ} \mathrm{C}$ ) nas primeiras duas e decrescente até o término da secagem. Após as sementes foram armazenadas, nas condições ambientais por 180 dias e analisadas quanto a qualidade aos zero, 90 e 180 dias, através dos testes de germinação, primeira contagem da germinação, envelhecimento acelerado, frio sem solo e emergência de plântulas em campo. Concluiu-se que a secagem intermitente empregando temperatura constante do ar a $60^{\circ} \mathrm{C}$ afeta negativamente a qualidade fisiológica de semente de arroz e que o uso de temperaturas crescentes até $60^{\circ} \mathrm{C}$ na secagem intermitente proporciona a manutenção da qualidade fisiológica de sementes de arroz.
\end{abstract}

Termos para indexação: Oryza sativa, temperatura de secagem, qualidade fisiológica.

\section{INTERMITENTDRYING OF LOW LAND RICE SEEDS}

\begin{abstract}
This work aimed to maintain the physiological quality of rice seeds through the adequate use of air temperatures during the drying. The rice seeds cultivar El Paso L-144 were dried in an intermittent drying system, with capacity for $11.000 \mathrm{~kg}$, under four drying conditions: 1) at constant temperature of $40^{\circ} \mathrm{C}$; 2) constant temperature of $60^{\circ} \mathrm{C}$; 3) at gradual increasing temperature (since $60^{\circ} \mathrm{C}$ ) during the first two hours and constant temperature of $60^{\circ} \mathrm{C}$ until the end of the drying cycle; 4 ) at gradual increasing temperature $\left(\right.$ since $60^{\circ} \mathrm{C}$ ) in the first two hours and gradual decreasing temperature until the end of drying cycle. The seeds were kept in bags made of trussed plastic yarns at room temperature and local environment conditions, for the period of 180 days and analyzed how much the physiological quality at zero, 90 and 180 days. The storage system was conventional. The vigour (through accelerated aging, field emergency test and cold test) test were analyzed. In conclusion, the intermittent drying process at a constant temperature of $60^{\circ} \mathrm{C}$ is don't preserves the seed quality; finally, the gradual increased temperature also preserves the physiological quality of rice seed.
\end{abstract}

Index terms: Oryza sativa, drying temperature, physiological quality.

\section{INTRODUÇÃO}

O aumento de produtividade ocorrido na cultura de arroz irrigado no decorrer dos anos, está diretamente ligado ao ganho tecnológico com a implantação de lavouras de qualidade, sendo

\footnotetext{
${ }^{1}$ Submetido em 12/12/2006. Aceito para publicação em 30/03/2007. Parte da tese de doutorado do primeiro autor apresentada ao Programa de Pósgraduação em Ciência e Tecnologia de Sementes .

${ }^{2}$ Eng $^{\circ}$. Agrícola, Dr., Ricetec, Laboratório de Qualidade Industrial.
}

a semente um dos insumos que mais influencia nessa característica.

A tecnologia para a produção de sementes de alta qualidade preconiza, genericamente, a execução da colheita no momento mais próximo possível da maturidade fisiológica.

\footnotetext{
csaravia.@terra.com.br

${ }^{3}$ Eng ${ }^{\circ}$.Agrícola, Dr., Professor Adjunto, FEA, UFPel, wolperes@uol.com.br ${ }^{4}$ Graduando em Engenharia Agrícola, UFPel, joelrisso@gmail.com.
} 
A medida que o período de permanência no campo, pósmaturidade fisiológica aumenta, diminui a qualidade da semente. Da mesma forma, na recepção das sementes de arroz, mantê-las úmidas na moega, sem aeração, por período superior a 24 horas, pode reduzir a qualidade e conservabilidade no posterior armazenamento (Elias, 1998).

A qualidade fisiológica das sementes influencia diretamente a população inicial de plantas, refletindo no rendimento da cultura. O conjunto de propriedades que determina um rápido estabelecimento da população de plantas em campo, assim como seu desenvolvimento, sob várias condições ambientais é o vigor (Krzyzanowsky e França Neto, 1999).

Ao atingir a maturidade fisiológica, a semente se torna independente fisiologicamente da planta e, segundo características higrométricas do ar exterior, perde água mais ou menos rapidamente até o momento da colheita. As precipitações pluviais podem reumedecer as sementes já secas e o tempo frio e úmido pode retardar a perda de água (Villela e Peske, 2004).

A medida que avança o tempo de pós-maturidade, diminui, também, a resistência das sementes ao ataque de pragas e microrganismos. A colheita, portanto, deve ser realizada no momento propício e de forma adequada. Colheita realizada na faixa de umidade recomendada minimiza as perdas, mas requer o uso de secagem artificial (Elias, 2002b).

Na secagem artificial ao mesmo tempo em que o ar fornece calor ao sistema, ele absorve água do produto na forma de vapor. As sementes, sendo higroscópicas, sofrem variações no seu teor de água de acordo com as condições do ambiente. Quando entram em contato com o ar, realizam trocas até que sua pressão de vapor e a temperatura tenham valores semelhantes, atingindo níveis de equilíbrio energético, hídrico e térmico. Entretanto, a temperatura do ar de secagem deve ser controlada, dentro de certos limites, evitando-se assim, possíveis danos físico-químicos e biológicos às sementes (Elias, 2002a).

A secagem intermitente é caracterizada pela passagem descontínua do ar pela massa de sementes, também em movimento, promovido pela recirculação das sementes no secador. Com isto, há difusão de água do interior para a periferia da semente, e a evaporação ocorre de maneira mais branda e equilibrada (Peres, 2001).

$\mathrm{O}$ armazenamento seguro depende da qualidade das sementes desde a lavoura, evitando-se o ataque de insetos no campo, os atrasos na colheita e as ocorrências de danos mecânicos durante os processos envolvidos. Além do mais, independentemente do grau de tecnologia empregado, a limpeza do local destinado ao armazenamento é de fundamental importância (Silva, 2000).

O presente trabalho objetiva a minimização das perdas na qualidade fisiológica nas sementes de arroz pelo adequado uso de temperaturas de condicionamento do ar durante a secagem intermitente.

\section{MATERIALE MÉTODOS}

O experimento foi conduzido na Cooperativa Alegretense de Arroz, localizada no município de Alegrete e no Departamento de Fitotecnia da Universidade Federal de Pelotas.

Foram utilizadas sementes de arroz (Oryza sativa L.) irrigado, cultivar EL Paso L-144, colhidas na safra 2003/ 2004 na região oeste do Rio Grande do Sul.

As sementes de arroz foram colhidas com teor de água de $18,3 \%$ com colhedora automotriz de ceifa e trilha, submetidas a pré-limpeza em máquina de ar e peneiras e após permaneceram em silo pulmão até o carregamento do secador. A secagem foi realizada em secador industrial intermitente de bandejas, marca Pampeiro, fluxo misto, com capacidade estática de $11000 \mathrm{~kg}$ de arroz As sementes foram submetidas a quatro tratamentos, correspondente a manejos da temperatura do ar de secagem:

1) secagem a temperatura do ar constante a $40^{\circ} \mathrm{C}(\mathrm{C} 40)$;

2) secagem com temperatura do ar constante a $60^{\circ} \mathrm{C}$ (C60);

3) secagem com temperatura do ar crescente até $60^{\circ} \mathrm{C}$ nas primeiras duas horas de secagem e a partir da segunda hora constante a $60^{\circ} \mathrm{C}$ até o término do processo (C60C);

4) secagem com temperatura do ar crescente até $60^{\circ} \mathrm{C}$ nas primeiras duas horas e decrescente até o término da secagem (C60D).

Após a secagem, as sementes provenientes dos quatro tratamentos de secagem, permaneceram armazenadas em pilhas de 220 sacos cada uma, sob condições ambientais ( $\mathrm{t}=12$ a $24^{\circ} \mathrm{C}$ e UR $=74$ a $87 \%$ ), em armazém convencional, acondicionadas em embalagens de polipropileno trançado de $50 \mathrm{~kg}$, por 180 dias, com avaliação da qualidade realizada aos zero, 60 e 180 dias, através dos seguintes testes:

Germinação: realizado conforme as Regras para Análise de Sementes - RAS (Brasil, 1992), utilizando substrato de papel toalha umedecido com água destilada na proporção de 2,5 vezes o peso do papel seco. O germinador foi regulado à temperatura constante de $25^{\circ} \mathrm{C}$ e as avaliações realizadas aos 
sete e aos quatorze dias após a semeadura

Frio sem solo: sementes foram semeadas de forma similar às submetidas ao teste de germinação e os rolos colocados em sacos plásticos e mantidos durante sete dias em câmara a temperatura de $10^{\circ} \mathrm{C}$. Após este período, os rolos foram levados a um germinador regulado à temperatura de $25^{\circ} \mathrm{C}$ A avaliação foi realizada no sétimo dia.

Envelhecimento acelerado: realizado em caixas gerbox adaptadas contendo no interior, uma bandeja com tela onde foram distribuídas 400 sementes. No interior das caixas foi acondicionado $40 \mathrm{ml}$ de água destilada e após a vedação, as caixas foram mantidas a $42^{\circ} \mathrm{C}$, durante 96 horas (Marcos Filho, 2005). Encerrado o período de envelhecimento, as sementes foram submetidas ao teste de germinação, conforme metodologia descrita anteriormente. A avaliação foi realizada no sétimo dia.

Emergência de plântulas em campo: a semeadura foi realizada aos 180 dias após a secagem das sementes, sendo as amostras coletadas aos zero e 90 dias após a secagem, mantidos em câmara fria e seca $\left(t=15^{\circ} \mathrm{C}\right.$ e $\left.\mathrm{UR}=40 \%\right)$ até o momento da instalação do teste. A semeadura foi realizada mantendo a distância entre as sementes na linha de $2 \mathrm{~cm}$ e entre linhas de $8 \mathrm{~cm}$ e a profundidade de $3 \mathrm{~cm}$, empregando quatro repetições de 50 sementes. A contagem das plântulas emergidas foi realizada aos 21 dias após a semeadura.

Antes das análises, os dados de germinação, primeira contagem da germinação, envelhecimento acelerado, teste de frio e emergência das plântulas em campo, sofreram transformação arco seno. Para facilitar a interpretação dos parâmetros avaliados, os resultados foram apresentados por médias dos valores originais.

Utilizou-se delineamento experimental inteiramente casualizado, em esquema fatorial $4 \times 3$ (manejos da temperatura do ar de secagem e tempos de armazenamento), com quatro repetições. As médias foram comparadas pelo teste de Tukey, a 5\% de significância.

\section{RESULTADOS E DISCUSSÃO}

Imediatamente após a secagem empregando diferentes manejos da temperatura do ar, as sementes atingiram teores de água médios de 13,4, valor adequado para o armazenamento de sementes de arroz conforme descrito por Baudet (2004). Aos 90 dias, as sementes alcançaram teor de água médio de 13,8\% e aos 180 dias atingiram 13,1\% confirmando a tendência de sofrer variações conforma as condições ambientais, em função do caráter dinâmico do equilíbrio higroscópico.

Verifica-se na Tabela 1 que não houve diferença significativa entre os manejos da temperatura do ar de secagem no início do armazenamento, evidenciando que esses manejos não causaram efeitos imediatos prejudiciais na germinação das sementes.

Aos 90 e 180 dias de armazenamento constatou-se desempenho inferior das sementes submetidas à secagem a temperatura constante de $60^{\circ} \mathrm{C}$ em relação aos demais tratamentos.

Através da análise dos valores absolutos apresentados ao longo do período de armazenamento, observa-se, de uma maneira geral, redução do poder germinativo no decorrer do armazenamento para todos os manejos. Entretanto, mesmo ao final dos 180 dias, os resultados permaneceram acima dos padrões mínimos para a produção de sementes no Rio Grande do Sul (2000), que estabelecem germinação mínima de 80\%.

Os resultados obtidos na primeira contagem da germinação (Tabela 2) permitem constatar que as sementes submetidas aos diferentes manejos de temperatura do ar de secagem apresentaram comportamentos semelhantes aos zero

TABELA 1. Germinação (\%) de sementes de arroz, cultivar El Paso L-144, submetidas a quatro manejos da temperatura do ar de secagem, sob três períodos de armazenamento.

\begin{tabular}{lccc}
\hline Manejo na temperatura & \multicolumn{3}{c}{ Dias de armazenamento } \\
\cline { 2 - 4 } do ar de secagem & Zero & 90 & 180 \\
\hline (C40) & $98 \mathrm{a}$ & $96 \mathrm{a}$ & $95 \mathrm{a}$ \\
$(\mathrm{C} 60)$ & $97 \mathrm{a}$ & $88 \mathrm{~b}$ & $83 \mathrm{~b}$ \\
$(\mathrm{C} 60 \mathrm{C})$ & $98 \mathrm{a}$ & $95 \mathrm{a}$ & $93 \mathrm{a}$ \\
$(\mathrm{C} 60 \mathrm{D})$ & $97 \mathrm{a}$ & $94 \mathrm{a}$ & $93 \mathrm{a}$ \\
\hline
\end{tabular}

Letras minúsculas distintas na mesma coluna, correspondem a diferenças significativas, pelo teste Tukey a 5\% de significância.

TABELA2. Primeira contagem da germinação (\%) de sementes de arroz, cultivar El Paso L-144, submetidas a quatro manejos da temperatura do ar de secagem, sob três períodos de armazenamento.

\begin{tabular}{lccc}
\hline Manejo na temperatura & \multicolumn{3}{c}{ Dias de armazenamento } \\
\cline { 2 - 4 } do ar de secagem & Zero & 90 & 180 \\
\hline$(\mathrm{C} 40)$ & $92 \mathrm{a}$ & $90 \mathrm{a}$ & $87 \mathrm{a}$ \\
$(\mathrm{C} 60)$ & $84 \mathrm{~b}$ & $79 \mathrm{~b}$ & $70 \mathrm{c}$ \\
$(\mathrm{C} 60 \mathrm{C})$ & $88 \mathrm{a}$ & $86 \mathrm{a}$ & $81 \mathrm{~b}$ \\
$(\mathrm{C} 60 \mathrm{D})$ & $87 \mathrm{a}$ & $86 \mathrm{a}$ & $81 \mathrm{~b}$ \\
\hline
\end{tabular}

Letras minúsculas distintas na mesma coluna, correspondem a diferenças significativas, pelo teste Tukey a 5\% de significância. 
e 90 dias, exceto a secagem a temperatura constante de $60^{\circ} \mathrm{C}$ que afetou negativamente o vigor das sementes.

Aos 180 dias, as sementes secadas a temperatura constante de $40^{\circ} \mathrm{C}$ apresentaram desempenho superior, as secadas a temperatura crescente até $60^{\circ} \mathrm{C}$ e constante ou decrescentes até o final tiveram desempenho intermediário e as secadas a temperatura constante de $60^{\circ} \mathrm{C}$ mostraram desempenho inferior.

Os resultados mostraram que ao longo do período de armazenamento ocorreu, de uma maneira geral, redução do vigor das sementes, avaliados pela primeira contagem da germinação, sendo mais acentuada nas sementes submetidas à secagem a temperatura constante de $60^{\circ} \mathrm{C}$.

Segundo Tekrony (1995), através do teste de envelhecimento acelerado, é possível classificar um lote de sementes como de alto vigor quando os resultados são superiores a $80 \%$, vigor médio entre 60 e $80 \%$ e baixo quando inferior a $60 \%$.

Pelos dados da Tabela 3 e baseado na classificação sugerida proposta por Tekrony (1995) é tangível classificar as sementes submetidas à secagem com temperatura do ar constante a $40^{\circ} \mathrm{C}$ e às secagens com temperaturas variáveis como sementes de alto vigor. $\mathrm{O}$ tratamento de secagem em

TABELA3. Envelhecimento acelerado (\%) de sementes de arroz, cultivar El Paso L-144, submetidas a quatro manejos da temperatura do ar de secagem, sob três períodos de armazenamento.

\begin{tabular}{lccc}
\hline Manejo na temperatura & \multicolumn{3}{c}{ Dias de armazenamento } \\
\cline { 2 - 4 } do ar de secagem & 0 & 90 & 180 \\
\hline (C40) & $86 \mathrm{a}$ & $83 \mathrm{a}$ & $82 \mathrm{a}$ \\
(C60) & $74 \mathrm{~b}$ & $71 \mathrm{~b}$ & $69 \mathrm{~b}$ \\
$(\mathrm{C} 60 \mathrm{C})$ & $84 \mathrm{a}$ & $83 \mathrm{a}$ & $80 \mathrm{a}$ \\
(C60D) & $85 \mathrm{a}$ & $83 \mathrm{a}$ & $81 \mathrm{a}$ \\
\hline
\end{tabular}

Letras minúsculas distintas na mesma coluna, correspondem a diferenças significativas, pelo teste Tukey a 5\% de significância.

TABELA 4. Teste de frio (\%) de sementes de arroz, cultivar El Paso L-144, submetidas a quatro manejos da temperatura do ar de secagem, sob três períodos de armazenamento.

\begin{tabular}{lccc}
\hline Manejo na temperatura & \multicolumn{3}{c}{ Dias de armazenamento } \\
\cline { 2 - 4 } do ar de secagem & 0 & 90 & 180 \\
\hline (C40) & $76 \mathrm{a}$ & $77 \mathrm{a}$ & $76 \mathrm{a}$ \\
$(\mathrm{C} 60)$ & $69 \mathrm{~b}$ & $67 \mathrm{~b}$ & $65 \mathrm{c}$ \\
(C60C) & $75 \mathrm{a}$ & $75 \mathrm{a}$ & $73 \mathrm{~b}$ \\
(C60D) & $78 \mathrm{a}$ & $74 \mathrm{a}$ & $72 \mathrm{~b}$ \\
\hline
\end{tabular}

Letras minúsculas distintas na mesma coluna, correspondem a diferenças significativas, pelo teste Tukey a 5\% de significância. que foi utilizada temperatura do ar constante a $60^{\circ} \mathrm{C}$ proporcionou sementes classificadas como médio vigor.

Constata-se que o teste de frio (Tabela 4) apresentou sensibilidade para identificar diferenças entre os tratamentos de secagem, mostrando comportamento similar ao verificado na primeira contagem da germinação (Tabela 2). Esses resultados concordam com Peters (1992) ao destacar a eficiência deste teste na avaliação da qualidade fisiológica das sementes de arroz.

O teste de frio pode funcionar como um instrumento de grande valor para seleção prévia de sementes que apresentam bom potencial de emergência em solos frios e úmidos, condições estas que são normalmente encontradas em semeaduras a partir de setembro a meados de outubro na região sul do Brasil, conforme Krzyzanowsky e França Neto (1999).

O teste de emergência em campo, conforme Carvalho (1994) pode fornecer uma boa previsão da potencialidade do lote, quando conduzido na época recomendada para a semeadura da espécie.

A análise da Tabela 5 permite visualizar que os valores encontrados estão mais próximos aos obtidos no teste de germinação do que em relação aos encontrados na primeira contagem da germinação, no teste de frio e no envelhecimento acelerado. Isso se deve, provavelmente, ao fato de as condições ambientais terem sido favoráveis durante a condução do teste de emergência em campo.

Uma análise geral dos resultados obtidos permite verificar que o emprego de temperatura do ar de secagem crescentes até $60^{\circ} \mathrm{C}$ por duas horas seguido de temperaturas decrescentes até o final da secagem não causam efeitos imediatos prejudiciais à qualidade fisiológica de sementes de arroz. Entretanto, o uso de temperatura constante de $60^{\circ} \mathrm{C}$ ocasiona danos imediatos e latentes à qualidade de sementes de arroz.

TABELA 5. Emergência de plântulas a campo (\%), de sementes de arroz, cultivar El Paso L-144, submetidas a quatro manejos da temperatura do ar de secagem, sob três períodos de armazenamento.

\begin{tabular}{lccc}
\hline Manejo na temperatura & \multicolumn{3}{c}{ Dias de armazenamento } \\
\cline { 2 - 4 } do ar de secagem & 0 & 90 & 180 \\
\hline (C40) & $90 \mathrm{a}$ & $89 \mathrm{a}$ & $87 \mathrm{a}$ \\
$(\mathrm{C} 60)$ & $84 \mathrm{~b}$ & $82 \mathrm{~b}$ & $78 \mathrm{~b}$ \\
$(\mathrm{C} 60 \mathrm{C})$ & $91 \mathrm{a}$ & $88 \mathrm{a}$ & $86 \mathrm{a}$ \\
$(\mathrm{C} 60 \mathrm{D})$ & $90 \mathrm{a}$ & $88 \mathrm{a}$ & $85 \mathrm{a}$ \\
\hline
\end{tabular}

Letras minúsculas distintas na mesma coluna, correspondem a diferenças significativas, pelo teste Tukey a 5\% de significância. 


\section{CONCLUSÕES}

A secagem intermitente empregando temperatura constante do ar a $60^{\circ} \mathrm{C}$ afeta negativamente a qualidade fisiológica de semente de arroz.

$\mathrm{O}$ uso de temperatura crescente até $60^{\circ} \mathrm{C}$ na secagem intermitente proporciona a manutenção da qualidade fisiológica de sementes de arroz.

\section{REFERÊNCIAS}

BAUDET, L. Armazenamento de sementes de arroz irrigado. I.: PESKE, S.T.; Schuch, L.O.B.; BARROS, A.C.S.A. Produção de sementes de arroz irrigado. 2004. p.481-498.

BRASIL. Ministério da Agricultura e da Reforma Agrária. Regras para análise de sementes. Brasília: SNDA/DNDV/CLAV, 1992. 365p.

CARVALHO, N. M. O conceito de vigor em sementes. In: VIEIRA, R.D.; CARVALHO, N.M. Testes de vigor em sementes. Jaboticabal: FUNEP, 1994. p. 1-25.

ELIAS, M.C. Armazenamento e conservação de grãos em médias e pequenas escalas. Pelotas, 2002. Pólo de Inovação Tecnológica em Alimentos da Região Sul. UFPEL-FAEM-DCTA, 2002a. 218p.

ELIAS, M.C. Aeração em armazenamento de grãos. In: LORINI, I.; MIIKE, L.H.; SCUSSEL, V.M. Armazenagem de grãos. Campinas: IBG, p.311-359, 2002b.

ELIAS, M.C. Efeitos da espera para secagem e do tempo de armazenamento na qualidade das sementes e grãos do arroz irrigado. Pelotas, 1998. 164f. Tese (Doutorado em Ciência e Tecnologia de Sementes) - Faculdade de Agronomia "Eliseu Maciel”, Universidade Federal de Pelotas, 1998.

KRZYZANOWSKY, F. C.; FRANÇA NETO, J. B. Testes de vigor em sementes. In: Encontro sobre avanços em tecnologia de sementes. Pelotas: FAEM/UFPel, 1999. 111p.

MARCOS FILHO, J. Fisiologia de sementes de plantas cultivadas. Piracicaba: FEALQ, 2005. 495p.

PERES, W.B. Manutenção da qualidade de grãos. Pelotas: Editora e gráfica da UFPel, 2001. 78p.

PETERS, A. C. Avaliação de testes de vigor em sementes de arroz (cv BR IRGA 414) e suas relações com a emergência a campo. 1992. 44f. Dissertação (Mestrado em Ciência e Tecnologia de Sementes) - Faculdade de Agronomia Eliseu Maciel, Universidade Federal de Pelotas, 1992.

RIO GRANDE DO SUL. Secretaria da Agricultura e Abastecimento. Departamento de Produção Vegetal. CESM/RS. Normas e padrões de produção de sementes e mudas para o Estado do Rio Grande do Sul. Porto Alegre, 2000. 156p.

SILVA, J.S. Secagem e armazenagem de produtos agrícolas. Viçosa: Aprenda Fácil, 2000. 502p.

TEKRONY, M. A. S. Accelerated ageing. In: HAMPTON, J. G.; TEKRONY, D. M. Handbook of vigour test methods. 1995. p. 3550 .

VILLELA, F. A.; PESKE, S. T. Secagem e beneficiamento de sementes de arroz irrigado. In: PESKE, S.T.; SCHUCH, L.O.B.; BARROS, A.C.S.A. Produção de sementes de arroz irrigado. 2004. p.445-479. 